\title{
Perceptions of Healthcare Services Students on Older Peoples and Ageing
}

\author{
(1) Sinan Yenal1, (1D Kerziban Yenal2 \\ ${ }^{1}$ Dokuz Eylül University, Vocational School of Healthcare Services, Department of Ambulance and Emergency Services, Izmir, Turkey \\ 2European University of Lefke, School of Healthcare Sciences, Department of Nursing, Lefke, Cyprus/Republic of Turkish
}

\begin{abstract}
Objective: This study was conducted to evaluate the perception of older people and ageing among students of a Vocational School of Healthcare Services.

Materials and Methods: This descriptive research was conducted on students receiving education in a vocational school of health services during the 2018-2019 academic year. Data were collected using the attitudes toward aging and elderliness scale. Moreover, an additional form was prepared to evaluate the personal information about the students.

Results: The study was conducted on 669 students. The mean total attitudes toward aging and elderliness scale score was $2.86 \pm 0.6$. When all the subscale scores of the attitudes toward aging and elderliness scale were examined, the lowest score was in the perception of the difficulty accepting old age $(2.78 \pm 0.79)$, whereas the highest score was in the perception of the difficulty coping with life $(3.19 \pm 0.73)$. Gender, presence of a person aged $\geq 65$ years in the family and having lived with an older person in the same house at a certain period in life did not have an effect on the perception of old age and ageing.
\end{abstract}

Conclusion: The results of this study showed that students of the Vocational School of Healthcare Services had an average level of perception regarding ageing and old age. Considering the rapidly ageing population worldwide, it is important to help and guide healthcare technicians develop positive perceptions about older people.

Keywords: Ageing, elderly, perception, student

\section{Introduction}

A rapidly ageing of the population and changes in the family structure are hot debates in the modern world. This phenomenon underlined the importance of services being provided to the older people. Old age involves living with social relationships in a social environment. The boosted health problems with ageing increase the demand of the elderly population for healthcare services (1). Older people become sick more often, have to live with more chronic diseases or disorders, are challenged by multiple health problems at the same time and are, thus, more frequently admitted to healthcare centres and stay longer at the hospitals (2).

The Vocational School of Healthcare Services (VSHS) in Turkey is a four semester pre-university school incorporation with the medical faculty. In the VSHS there are 27 different active programs (3-5).

Students studying healthcare services provide services to people from every age group during their professional life, their opinions regarding old age and ageing are important (1). Because the vocational school of higher education students will be a part of the healthcare team in the future, developing a more affirmative, respectful and tolerant behaviour and attitude towards older people and ageing will be more beneficial in providing healthcare services (6).

This study was conducted to evaluate the perceptions of students of the VSHS on older people and ageing.

Address for Correspondence: Sinan Yenal, Dokuz Eylül University, Healthcare Services Vocational School, Department of Ambulance and Emergency Services, İzmir, Turkey

E-mail: sinan.yenal@deu.edu.tr ORCID: orcid.org/0000-0001-9352-5938

Received: Aug 05, 2019 Accepted: Aug 15, 2019

Cite this article as: Yenal S, Yenal K. Perceptions of Healthcare Services Students on Older Peoples and Ageing. Eur J Geriatr Gerontol 2019;1(2):46-50

๑Copyright 2019 by the Academic Geriatrics Society / European Journal of Geriatrics and Gerontology published by Galenos Publishing House. 


\section{Materials and Methods}

This descriptive research was conducted on students studying in Dokuz Eylül University VSHS during the 2018-2019 academic year. This study was conducted on seven different program students: Paramedic program, Medical documentation and secretariat program, Medical laboratory program, Opticianry program, Medical imaging program, Anaesthesia program and Radiotherapy program. No specific method for sample selection was conducted, and the entire student population was aimed to be enrolled in the analysis. Students who rejected to participate in the study, those who had ceased the school temporarily on the date of the research, those who could not be reached in the school on the date of research and those aged $<18$ years were excluded. Thus, the study was completed by reaching 669 (57.4\%) of 1,164 students who comprised the study population. Figure 1 shows the derivation of the sample used in this study.

Data were collected using the Attitude scale toward aging and elderliness (ASTAE), the validity and reliability study of which was conducted by Otrar (7). This is a self-administered, 5-point Likert-type scale containing four subscales and 45 items. The "difficulty of accepting elderliness" subscale comprises 12 items, the "social exhaustion perception" subscale comprises 15 items, the "difficulty of coping with life" subscale comprises 10 items and the "negative image" subscale comprises eight items. The total score in each subscale is calculated by dividing the sum of all items to the total number of items in the subscale. A higher score in a particular subscale is interpreted as an increase in the characteristic that names the subscale. Higher total scale scores indicate negative attitudes in general, whereas lower total scale

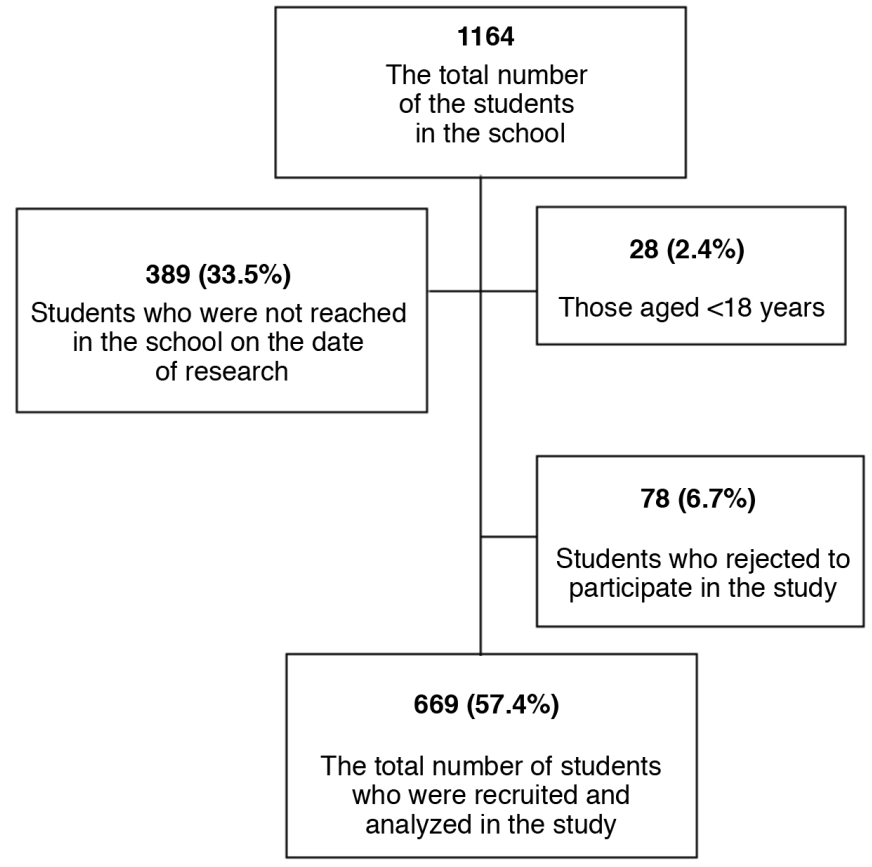

Figure 1. Flowchart showing the derivation of the sample used in this study. scores indicate positive attitudes and perception towards old age (7).

Further, an additional form was prepared to evaluate the personal information of students. This form was used to collect data such as age, gender, monthly income of the family, the presence of a person aged $\geq 65$ years in the family and the state and duration of living in the same house with a person aged $\geq 65$ years.

Data were collected inside the classroom during the hours when students did not have a lecture in October 2018. They were given 10-15 min to fill in the measurement tools, and the filled forms were then collected by the researcher. All students provided informed consent before participation. This study was approved by the Dokuz Eylül University Non-interventional Research Ethics Committee (approval no: 2018: 26-02).

\section{Statistics}

Data were evaluated using SPSS for Windows 18.0 software package. Independent samples t-test was used to compare ASTAE scores with gender, the presence of a person aged $\geq 65$ years in the family and duration of living in the same house with a person aged $\geq 65$ years.

\section{Results}

Of the participating students, $67.3 \%$ were females. The mean age of the students was $19.4 \pm 2.1$ years. Further, $44.3 \%$ of the students had middle income. Among the students, $48.1 \%$ of responded "yes" to the question "is there anyone at or above the age of 65 alive in your family?" and 52.6\% of the students responded "yes" to the question "did you live in the same house with an older person?"

The total scale and subscale scores of students are presented in Table 1. The lowest score was noted in subscale 2 (social exhaustion perception), and the highest score was noted in subscale 3 (perception of coping with life).

The comparison of the total scale and subscale scores of students according to gender are presented in Table 2. Male and female students achieved similar total scale and subscale scores related to the perception of old age.

The effect of the presence of a person aged $\geq 65$ years in the family on the perception of ageing and old age is presented in

Table 1 . Total scale and subscale scores of students $(n=669)$

\begin{tabular}{|l|c|c|}
\hline & $\bar{X}$ & $\mathbf{S}$ \\
\hline Subscale 1 (difficulty of accepting elderliness) & 2.78 & 0.79 \\
\hline Subscale 2 (social exhaustion perception) & 2.72 & 0.58 \\
\hline Subscale 3 (difficulty of coping with life) & 3.19 & 0.73 \\
\hline Subscale 4 (negative image) & 2.84 & 0.66 \\
\hline Total & 2.86 & 0.60 \\
\hline
\end{tabular}


Table 3. There was no statistically significant difference between the groups when students were compared according to their ASTAE scores.

The effect of having lived in the same house with a person aged $\geq 65$ years on the perception of old age and ageing is shown in Table 4. Having lived in the same house with a person aged $\geq 65$ years did not have a significant effect on the perception of old age.

\section{Discussion}

This study has been one of the largest studies evaluating the perceptions of university students about ageing and elderliness. Of the participating students, 52\% reported that they lived in the same house with an older person for some time in their lives. This rate was $44 \%$ in a study of nursing students conducted by Aşiret et al. (8), 41\% in a study of VSHS students performed by Yetiş and Gürbüz (1), 45\% in a study of social services students reported by Ceylan and Öksüz (9), and 55\% in a study of nursing students conducted by Altay and Aydın (10) In another study,
Alquwez et al. (11) reported that 17\% of the Saudi Arabia nursing students lived together with older peoples at home. The results of the present research were in general consistent with those of other studies reported in Turkey.

In the analysis of ASTAE scores of the 669 students, the total scale and subscale scores indicated that students have a moderate level of perception regarding old age. In a study on university students performed by Dinçer et al. (12), students were found to have, in general, a positive attitude towards the older people. In different studies conducted on nursing and elder care students, students were shown to generally have a positive attitude towards the older people $(1,8,13)$. In a study written by Altay and Aydın (10), students exhibited a positive attitude towards older people discrimination. In a study by Yerli (14), no statistically significant difference was found between positive and negative attitudes of elder care students towards old age, although positive thoughts were more prominent. In a study on nursing students reported by Kulakçı (15), 64\% of students responded that they would find it difficult to accept

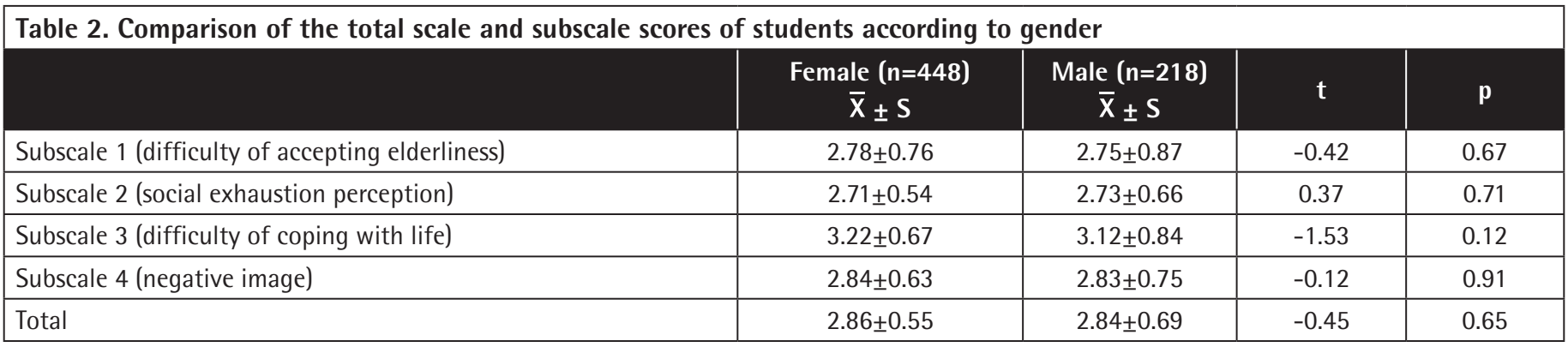

Table 3. Comparison of the total scale and subscale scores of students according to the presence of a person aged $\geq 65$ years in the family

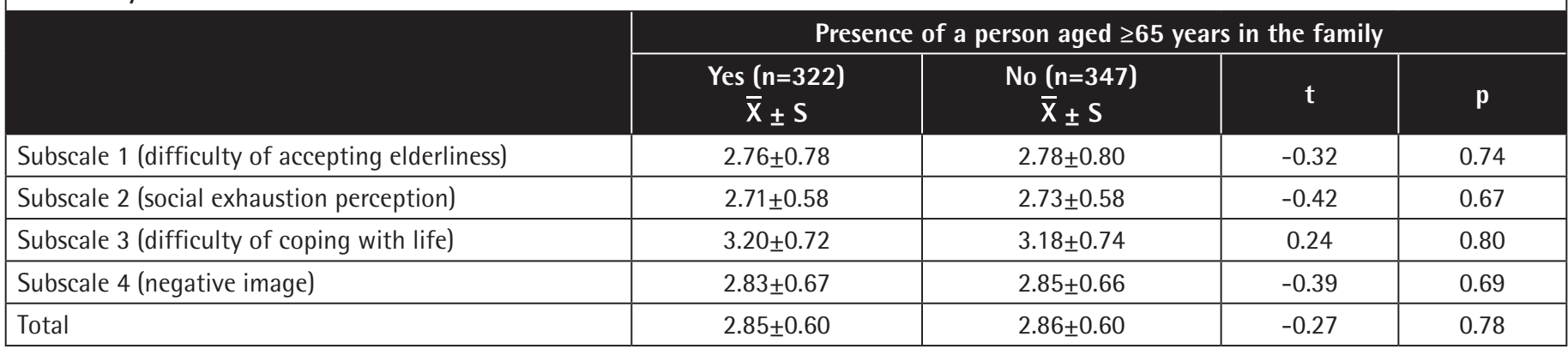

Table 4. Comparison of the total scale and subscale scores of students according to living in the same house with a person aged $\geq 65$ years

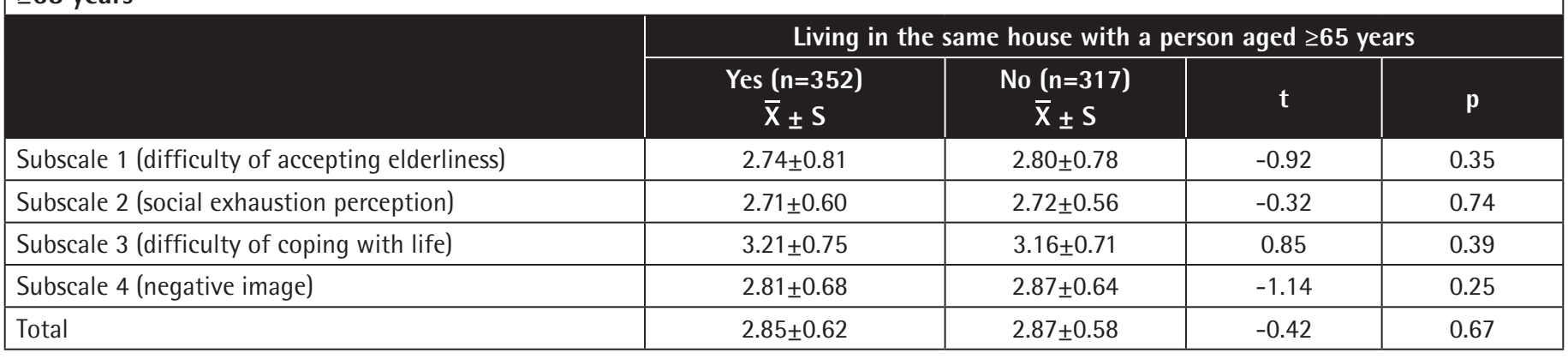


old age. In the same study, ageing was noted to be regarded as a social problem. Hsu et al. (16) the nurse students in China were shown to have positive attitudes toward older people. Ridgway et al. (17) reported that 75\% of participants among the British nursing students had moderately positive attitudes towards older people when the programme began, at the programme end this had increased to $98 \%$. Alquwez et al. (11) cited that the nursing students that have a near contact to the grandparents, have also positive attitudes toward older peoples. Wilson et al. (18) wrote that the medical studens had moderately positive attitudes towards older people. Cheong et al. (19) demonstrated that the medical students in Singapore have a positive attitude towards the older people. Results of the present study are consistent with those of other studies.

There was no statistically significant difference between female and male students in terms of their total scale and subscale scores reflecting their perception regarding old age. In studies conducted on nursing students, elder care students and social services students in Turkey and in different countries, the effects of gender on the perception about old people were analysed. These studies noted that gender has no effect on the perception about older people (2022). In a study by Şahin (23), gender was shown to have no effect on the attitude towards older people discrimination among university students. Alquwez et al. (11) demonstrated that gender have no effect attitude towards older people. Cheong et al. (19) reported also that gender have no effect attitude towards older people. Liu et al. (24) found on medical students also that gender have no effect attitude towards older people too. Only Hweidi and Al-Obeisat (25) reported that among the nurse students in Jordan that the gender has different attitude towards older people. In a study on finalyear students of the Social Services Department of the New South Wales University in Wales conducted by Heycox and Hughes (26), although the attitude of students towards the older people was reported to be moderate, female students had more favourable attitude towards the older people than male students. Results of the present study are consistent with those of other studies.

The presence of a person aged $\geq 65$ years in the family and having lived with an older person in the same house during a certain period of life had no significant effect on the perception about ageing and old age. Living with an older person had no effect on the perception of old age and ageing in a study by Abreu and Caldevilla (20) that compared students who live with an older person with those who do not live. Having lived with an older person was shown to have no effect on the total score in elderly discrimination in a study by Altay and Aydın (10). In the study by Aşiret et al. (8), having lived with an older person was shown to have no effect on the attitude towards the older people. In a study by Ceylan and Öksüz (9), no significant difference was found among the participating students in terms of living in the same house with an older person or people. In a study on nursing students conducted by Lambrinou et al. (27) to evaluate the attitudes of students towards the older people in Greece, having an older person in the family and living together with an older person was shown to not affect the attitudes of students towards the older people. Kim et al. (28) pointed out in a research from South Korea that the living together with older people had no effect on attitude towards older people. Results of the present study are also in accord with those of similar studies.

According to the results of the present study, VSHS students have a moderate level of perception about ageing and old age. It was considered that the students have not yet developed either a positive or negative perception about old age because the majority of students were at the beginning of their lives and had not yet started their professional careers. Having yet to enter the adulthood period of their lives may have directed them to be concerned more about the responsibilities of an adult, such as finding a job, starting a job, choosing a partner and serving in the army, instead of thinking about old age.

\section{Study Limitations}

This study has several limitations. First of all, it has been conducted only on students in VSHS, therefore, the results could not be generalised for the whole population but the new generation are in close contact with social media over the world. In addition, young age of the participants may have also caused them to view ageing as a too-distant-future.

\section{Conslusion}

Students being indecisive about old people and their inexperience may have affected the moderate level of perception about ageing among them in the present study. Considering the rapidly ageing population in Turkey as well as worldwide, it is important that healthcare technicians develop positive perceptions about old age and ageing. Therefore, it is important to include lectures on ageing in the syllabus for healthcare technicians. This will enable students in the young adulthood stage of their lives to provide more effective care after graduation to the older people who are at the final stage of their lives.

\section{Ethics}

Ethics Committee Approval: This study was approved by the Dokuz Eylül University Non-interventional Research Ethics Committee (approval no: 2018: 26-02).

Informed Consent: Informed consent was obtained from the patients.

Peer-review: Internally peer-reviewed. 


\section{Authorship Contributions}

Concept: S.Y., Design: K.Y., Data Collection or Processing: S.Y., Analysis or Interpretation: K.Y., Literature Search: S.Y., Writing: S.Y.

Conflict of Interest: No conflict of interest was declared by the authors.

Financial Disclosure: The authors declared that this study received no financial support.

\section{References}

1. Yetiş $G$, Gürbüz P. Determination of the health services vocational high school students' thoughts about the concept of age and elderly. Elderly Issues Research Journal (EIRJ) 2018;11:26-33.

2. Satar $S$, Sebe $A, A v c ı$ A, Karakuş $A$, icçme F. Emergency department and elderly patient. Cukurova Med J 2004;29:43-50.

3. Council of Higher Education: Vocational School Description: Law No. 2547. https://www.yok.gov.tr/Documents/Yayinlar/Yayinlarimiz/the-law-onhigher-education.pdf (Accessed: 11 February 2019).

4. Ministry Health, Council of Higher Education. Turkey health status report. https://www.saglik.gov.tr/TR,11659/saglik-bakanligi-turkiyede-saglikegitimi-ve-saglik-insangucu-durum-raporu-2014.html (Accessed: 11 February 2019).

5. Taştan R. Associate degree health profesions education in Turkey is 35 years old. Marmara Sağ Hiz Derg 2017;1:1-12.

6. Soyuer F, Ünalan D, Güleser N, Elmalı F. The attitudes of health vocational school students towards ageism and the relation of these attitudes with some demographical variablei. Mersin SBD 2010;3:20-25.

7. Otrar M. An attitude scale towards aging and elderliness: A validity and reliabilty study. Turkish J Sociol 2016;2:527-550.

8. Aşiret G, Kaymaz T, Canbolat Ö, Kapucu S. Attitudes of nurses towards older people. Society for Research and Development in Nursing 2015;17:10-20.

9. Ceylan $H$, Öksüz M. Analyzıng attitudes of undergraduate social work students towards ageism. J Int Soc Res 2015;8:459-466.

10. Altay $B$, Aydın T. Evaluation of the attitudes of nursing students towards ageism. Journal of Education and Research in Nursing 2015;12:11-18.

11. Alquwez N, Cruz JP, Almazan JU, Alamri MS, Mede JJ. The Arabic version of the kogan attitudes toward older people scale among Saudi nursing students: apsychometric analysis. Ann Saudi Med 2018;38:399-407.

12. Dinçer $Y$, Usta $E$, Bulduk $S$. How do university students view elderliness? Elderly Issues Research Journal (EIRJ) 2016;9:26-38.
13. Yazıcı SÖ, Kalaycı I, Kaya E, Tekin A. Attitudes of students in elderly care program towards ageism. Elderly Issues Research Journal 2015;2:77-87.

14. Yerli G. Elderly perception of the elder care students at Sakarya University vocational school of health. J Aca Soc Sci 2017:5:562-575.

15. Kulakçı $\mathrm{H}$. Evaluation of nursing students' ideas and views about old age and ageing in the first and fourth year of baccalaurate program in nursing. Dokuz Eylül University E J Nurs 2010;3:15-22.

16. Hsu MHK, Ling MH, Lui TL. Relationship between gerontological nursing education and attitude toward older people. Nurse Educ Today 2018;74:8590.

17. Ridgway W, Mason-Whitehead E, McIntosh-Scott A. Visual perceptions of aageing; a longitudinal mixed methods study of UK undergraduate student nurses' attitudes and perceptions towards older people. Nurse Education Today 2018;33:63-69.

18. Wilson MAG, Kurrle $S$, Wilson L. Medical student attitudes towards older people: a critical review of quantitative measures. BMC Research Notes 2018;11:71.

19. Cheong SK, Wong TY, Koh GC. Attitudes towards the elderly among Singapore medical students. Ann Acad Med Singap 2009;38:857-861.

20. Abreu M, Caldevilla N. Attitudes toward aging in Portuguese nursing students. Procedia-Soc Behav Sci 2015;171:961-967.

21. Ucun Y, Mersin S, Öksüz E. Attitudes towards elderly of youngs. J Int Soc Res 2015;8:1143-4119.

22. Danış MZ, Kara HZ. A research on university students' opinions about elderly. Ahi Evran University J Inst Soc Sci 2017;32:221-233.

23. Şahin H. Research on unıversıty students' attıtudes about elders and elder dıscrımınatıon. Turkish Journal of Geriatrics 2015;18:47-53.

24. Liu Z, Pu L, Wang H, Hu X. Survey of attitude towards and understanding of theelderly amongst chinese undergraduate medical students. Asian Biomedicine 2014;7:615-622.

25. Hweidi IM, Al-Obeisat SM. Jordanian nursing students' attitudes toward the elderly. Nurs Educ Today 2006;26:23-30.

26. Heycox K, Hughes M. Social work students' attitudes towards and interest in working with older people: an exploratory study. Advances in Social Work and Welfare Education 2006;8:6-14.

27. Lambrinou $E$, Sourtzi $P$, Kalokerinou $A$, Lemonidou C. Attitudes and knowledge of the greek nursing students towards older people. Nurse Education Today 2009;29:617-622.

28. Kim JH, Son GR, Algase DL. Attitudes toward the elderly among nursing students in Korea. Taehan Kanho Hakhoe Chi 2004;34:1499-1508. 